\title{
Disaster Preparedness in the Philippines: From the Will to the Way
}

\author{
Angel Vicario-Merino ${ }^{1 *}$, Noemi Muñoz-Agustín' ${ }^{2}$, Montserrat Ruiz-López1, \\ Jesús Guodemar-Pérez ${ }^{3}$, Juan Pablo Hervás-Pérez1 ${ }^{1}$ David Pérez-Manchón ${ }^{1}$ \\ ${ }^{1}$ Faculty of Education and Health, Camilo José Cela University, Madrid, Spain \\ ${ }^{2}$ International Cooperation Department, Spanish Red Cross, Madrid, Spain \\ ${ }^{3}$ Faculty of Physiotherapy, Camilo José Cela University, Madrid, Spain \\ Email: ^avicario@ucjc.edu,noemi@cruzroja.es,mrlopez@ucjc.edu,jguodemar@ucjc.edu,jphervás@ucjc.edu, \\ dpmanchon@ucjc.edu
}

How to cite this paper: Vicario-Merino, A., Muñoz-Agustín, N., Ruiz-López, M., Guodemar-Pérez, J., Hervás-Pérez, J. P., \& Pérez-Manchón, D. (2019). Disaster Preparedness in the Philippines: From the Will to the Way. Open Journal of Political Science, 9, 571-581.

https://doi.org/10.4236/ojps.2019.93034

Received: May 30, 2019

Accepted: July 23, 2019

Published: July 26, 2019

Copyright $\odot 2019$ by author(s) and Scientific Research Publishing Inc. This work is licensed under the Creative Commons Attribution International License (CC BY 4.0).

http://creativecommons.org/licenses/by/4.0/

\begin{abstract}
Geographically situated in the circle of fire in the Pacific and bordering the pacific tectonic plate, makes the Filipino archipelago one of the most disaster-prone areas in the world. As a result of this exposure, it is estimated that an annual USD 7.893 million are spent directly to the multi-hazard prevention, promotion and response, representing the $69 \%$ of social expenditure in the country. Multilevel efforts to prevent the results of the disasters hitting the Philippines have been developed, including the local, regional, country and regional areas. These efforts are being developed at operational and promotional levels, including the political initiatives at local, country and regional frameworks. There have been political efforts to create guidelines so as to work on disaster risk reduction and vulnerability reduction for the most vulnerable countries, with the first world conference held in 1994. The second one in Hyogo in 2005 produced a comprehensive guideline for the risk reduction for the most vulnerable countries, focusing on those most at risk like archipelagos, countries in high risk areas and high impact areas. There is a surprisingly small amount of literature published concerning the impact of the political initiatives and its impact on the health of such populated areas. The paper describes the responses generated by the Filipino government after Yolanda, based on the legal framework that Hyogo provided, as well as provides a literature review of the published manuscripts on different sources, finalising with several recommendations as the improvement of the coordination and communication between levels of implementation, the clarification of the real problems identified for each area and the coordination between all the actors involved (local government, INGOs, regional government, international initiatives...) in the DRR process in an area to avoid du-
\end{abstract}


plication of activities and looking forward to engaging in synergetic initiatives.

\section{Keywords}

Hyogo, DRR, Disaster Response, Preparedness, Vulnerability

\section{Introduction}

The Filipino archipelago is composed of over 7100 islands and is located in the Pacific ring of fire and the typhoon belt, experiencing an average of over 20 typhoons every year (Intergovernmental Panel on Climate Change, 2015). The Philippines is one of the three countries in the world with the highest exposure to climate hazards and is the country with the highest investment in the coastlines (Vereinte Nationen. \& Office for Disaster Risk Reduction, 2015) (Guha-Sapir et al., 2012).

There have been political efforts to create guidelines so as to work on disaster risk reduction and vulnerability reduction for the most vulnerable countries, with the first world conference held in 1994. The second one in Hyogo in 2005 produced a comprehensive guideline for the risk reduction for the most vulnerable countries, focusing on those most at risk like archipelagos, countries in high risk areas and high impact areas (Banwell, Rutherford, Mackey, \& Chu, 2018) (Asian Conference on Disaster Reduction 2006 (ACDR 2006), 2007).

The Philippines, matching clearly the criteria used this document to prepare its adaptation to its country, producing the NDRRMP by 2010 and approved by the RA 10212. There was special emphasis on the reduction of socio-economic vulnerabilities as preventative measures and included in the risk reduction for disasters (Alcayna, Bollettino, Dy, \& Vinck, 2016).

Their DRR mechanisms are strong and are a part of the mind-set of the community, but the legal framework has been missing for many years. The convergence of financial development, the DRR agreements and the climate change initiatives create an optimum scenario for the development of the policies required (Carabine, 2015).

The conference in Hyogo, Japan in 2010 produced the recommended legal framework for the Asia-Pacific countries to introduce into their respective legislations in terms of preparedness, response and recovery needs.

Despite the fact that the Strategic National Action Plan (SNAP) ("Philippines: Strategic national action plan (SNAP) for disaster risk reduction 2009-2019Policy, Plans \& Statements-Knowledge Base-PreventionWeb.net”, s. f.) for disaster risk reduction, a 10 year plan from 2009 until 2019, which follows the same roadmap as the Hyogo framework, this document was not implemented. It includes 18 priority programs with 150 strategic actions.

As a result, the Filipino government produced the National Disaster Response 
and Recovery Management Plan (NDRRMP), which adapted the Hyogo framework and the already existing SNAP to their legislation.

As a member of the Asia-Pacific Economic Cooperation (APEC) the Philippines takes part, where the disasters and its impact on the different country members is discussed ("APEC High Level Policy Dialogue on Disaster Resiliency-Thailand", s. f.). Within these high level policy meetings, the members agree upon activities such as: provision of businesses with tools to help them prepare for hazards, the promotion of community based approaches and research and education of the population as well as the promotion of public-private partnerships.

The NDRRMP got its legal support after the approval by the executive committee of the National DRRM Council and the final version was ready by December 2011, three years after the SNAP was approved.

These three key international policies developed by United Nations Frameworks were signed and approved in 2015 (Banwell et al., 2016):

1) The Sendai Framework, which focused on the reduction of disaster losses considering health, livelihood and lives, was signed by 187 member states. ("Asia meets to implement Sendai Framework-World", s. f.).

2) The sustainable Development Goals, which placed health as a main goal and linked to other SDGs, signed by 193 member states.

3) The Paris Agreement on Climate Change, signed by 195 countries.

With the documentation support in place, the legal background defined, the experience of the continuous activities in response to the annual disasters and the capacity to develop the activities, the impression was that the Philippines was one of the world countries in a good position to respond to emergencies.

\section{Methods}

The method used is a bibliographic and documental review of the published information concerning the Disaster Response and Recovery (DRR) in the Philippines and the response to super typhoon Hayian.

The key words used were: DRR Philippines, Asia-Pacific DRR, DRR framework.

The selection criteria used were: concerning the Philippines, after 2005, legal frameworks and the impact of frameworks on DRR and Super typhoon Hayian or Yolanda.

The exclusion criteria used were: before 2005, not concerning the Filipino archipelago, concerning other areas of DRR that did not include DRR or nationwide or area wide frameworks.

The discrimination process was done by reading the title and abstract / short summary provided. If the article met the criteria, the article was read and then accepted or rejected.

Within Pubmed the results were: 


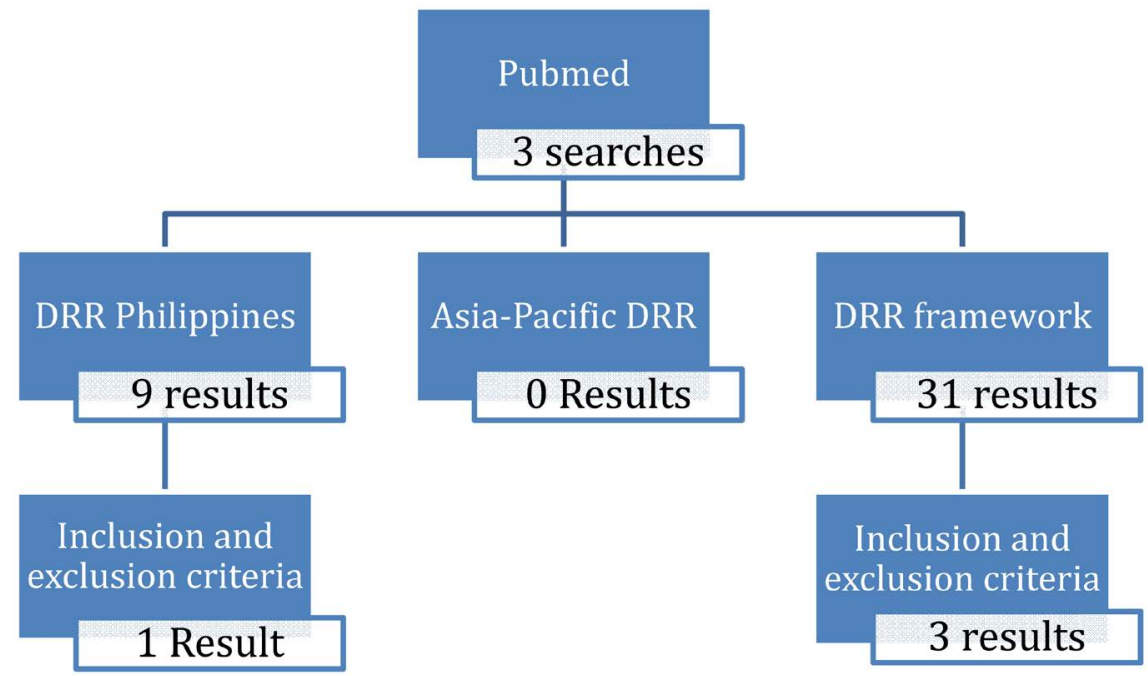

These academic documents did not provide the key documents, which were searched for using https://reliefweb.int/, a specialised site in DRR.

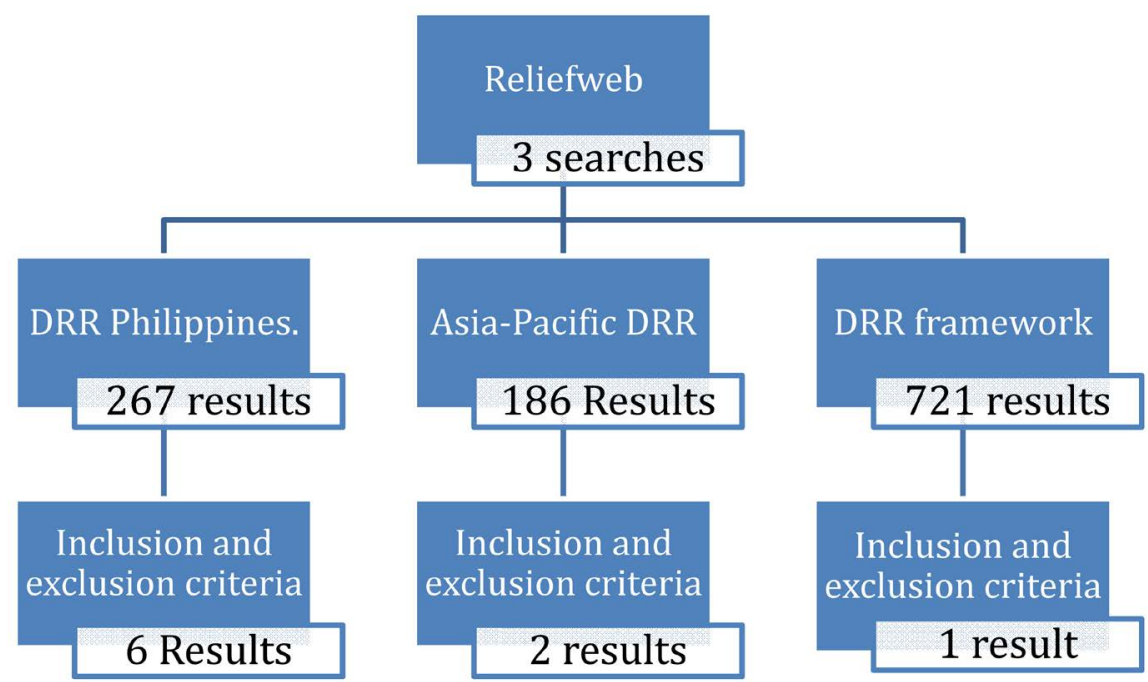

The legal documents reviewed to support the situation of the response of the Filipino community were complemented with the already existing academic studies published on the subject.

\section{Results}

\section{Legal background}

The Hyogo framework (Burkle et al., 2014) had as a result the National Disaster Risk Reduction and Management Plan (NDRRMP) (Brassard, Giles, \& Howitt, 2015), which followed the Hyogo initiative and created a single document where DRR was the main focus at all levels. This NDRRMP presented the roadmap for DRR in the Philippines for the following 5 years, 2010 to 2015.

\section{Hyogo framework}

Disaster mitigation, prevention and preparedness has been in the interna- 
tional agenda for over 20 years. In 1994 the "Yokohama Strategy for a safer world: guidelines for natural disaster prevention, preparedness and Mitigation" was approved. Over ten years had to pass by until 2005, when the UN called for a second World Conference on Disaster Reduction. It took place in Kobe, Hyogo, Japan and the document produced was the "Hyogo framework for action 2005-2015" (Burkle et al., 2014).

This second document had several differences from the first one in Yokohama (Egawa, MacIntyre, Beadling, Walsh, \& Shimomura, 2014), starting from the framing of the period in time until the next revision, supporting this way the commitment of keeping it a live document and a regular exercise.

The second difference is the approach to disasters, coming from a more reactive and post disaster management to a pro-active focus, where the preparation and preparedness measures aim at building the resilience of the communities and countries that are disaster prone. This new approach was approved and signed by 168 countries.

The expected outcome of the implementation of the framework is "the substantial reduction of disaster losses, in lives and in the social, economic and environmental assets of communities and countries" (Asian Conference on Disaster Reduction 2006 (ACDR 2006), 2007). The expected outcome is refined by three strategic goals, which are:

1) The integration of DRR into sustainable policies and planning.

2) Development and strengthening of institutions, mechanisms and capacities.

3) The incorporation of risk reduction approaches into the implementation of emergency preparedness, response and recovery programmes.

The strategic goals are divided into five priority areas (James, 2014):

1) DRR becomes a priority emphasising the facility of implementation.

2) Enhancement of the early warning systems

3) Building a culture of resilience and safety using knowledge, innovation and education.

4) Reduction of the underlying risk factors

5) Strengthening of all response levels.

These presented cross cutting issues which include; multi-hazard approaches, gender perspective and cultural diversity, community and volunteer participation and the capacity building and the transfer of technologies.

The framework has been formulated to continue providing tools for the achievement of the MDGs (Burkle et al., 2014).

\section{National Disaster Risk Reduction Management Plan (NDRRMP)}

The Hyogo framework of action (HFA) started a ripple effect on the countries, which in the case of the Philippines was represented by the enactment of the Republic Act 10212, which has become to be known as the Philippine Disaster Risk Reduction and Management Act of 2010.

The enactment of the RA 10212 (Brassard et al., 2015) created the basis for a shift in the approach, coming from a disaster preparedness and response to the strengthening of the DRR Management. 
The NDRRMP strengthens the resilience (Manyena, 2006) of the communities on disaster preparedness and response through the partnership of stakeholders, the National Government and Local Government Units (LGUs).

Following the Hyogo framework, the concept of vulnerability considers the socio-economic factors. It highlights the importance of mainstreaming the climate change adaptation and the DRR into the socioeconomic development planning, policy formulation and governance in the areas of environment, agriculture, water, energy, health, poverty reduction or land use among others through good governance.

With the implementation of the NDRRMP the Philippines will have:

"Safer, adaptive and disaster resilient Filipino communities towards sustainable development".

The way presented to achieve this objective is by prioritising four main areas as part of a whole and not taking them independently. These are:

1) Disaster prevention and mitigation

2) Disaster preparedness

3) Disaster response

4) Disaster recovery and rehabilitation

The implementation of the activities is intended to start by 2011, after the final approval. The activities have been divided into three main timelines:

- Short term 2011-2013

- Medium term 2014-2016

- Long term 2017-2028

\section{Strategic National Action Plan (SNAP)}

This document was intended to become a roadmap where the objectives in DRR, with the key objectives for the next 10 years would be collected. It would include the vision and the projection of the desired results, basing itself on the Hyogo Framework for action ("Philippines: Strategic national action plan (SNAP) for disaster risk reduction 2009-2019-Policy, Plans \& StatementsKnowledge Base-PreventionWeb.net", s. f.). To be able to arrive to the final SNAP document, it took information from the Four point action plan of action on disaster preparedness (4PPADP), published by the National Disaster Coordinating Council (NDCC), which included information on how to obtain positive information from key stakeholders.

For the period between 2009-2019 the SNAP includes the following:

- 18 priority programs and projects.

- Based on 150 strategic actions.

- All of which are clustered in 5 objectives

- Enabling environment.

- Mobilization of resources (financial and economic viability)

- Inclusiveness of the Filipino citizens in the decision making.

○ Enhancing safety

- Continuous Evaluation and development of DRR initiatives.

All of which have been consulted and agreed upon the main stakeholders in 
terms of DRR in the Philippines.

As of the finalization of this manuscript, the climate change initiative in the ASEAN area are still ongoing with frameworks such as "The ASEAN Vision 2025 " on DRR, where the member states are encouraged to develop and implement new strategies by 2020. (“Towards Policy Integration of Disaster Risk, Climate Adaptation, and Development in ASEAN", s. f.)

\section{Discussion}

The Hyogo's Framework for action operational plan was distributed for dissemination and approval in November 2006 and the Filipino NDRRMP was approved in 2010.

Typhoon Yolandac locked wind gusts over $210 \mathrm{Mph}$ falling under a category 5 typhoon, struck the Philippine islands on November 2013, seven years after the approval of the HFA and three years after the approval of the Filipino NDRRMP.

No country, no matter how well prepared may be, is ready to respond to such a disaster as Yolanda, but all the documents were already in place and some improvements should have happened since the approval in November 2011 until the disaster in November 2013.

The described challenges for collaboration on health DRR in the Philippines included as a main element the lack of available documents and awareness of DRR activities and available research (Banwell et al., 2016).

Unfortunately, the response mechanisms worked as they had been working until that moment: regional solidarity, support from neighbouring Regions and then the support from the National level. Prevention activities had not been enhanced other than the "traditional" ones such as the evacuation centres and the activities that the Filipino population had been developing previously... so there was already a way and a road to follow, at least documentation wise. Nevertheless, local governments are understaffed (Alcayna et al., 2016) and lack the means needed to implement the national policies.

As a result, all the DRR community based activities that are being developed and have been identified in previous studies (Alcayna et al., 2016) of the full disaster response cycles have identified important gaps, both at research and practical levels. One of the key gaps is the impossibility of mapping the activities of all the actors and identify who is doing what and where. From this point it is a challenge to go forward in a unified and coherent way.

Gaps in the basics for any research continue with the lack of a unified definition of community, continuing with a single way to measure social and capital as well as big limitations of access to marginalised groups of the communities (Kabil \& Kabeil, 2011).

Partnerships developed in the preparedness phase reviewed by previous studies (Carabine, 2015) Identified that the approach and initial intentions differ from what eventually took place and the stakeholders engagements. This ine- 
quality in the memberships become evident both in the preparedness and emergency response phase.

When these partnerships approach the capacity building of the local structures, the results obtained present a wide variety of responses, from human resource capacity building with training programs to the increase in institutional capacities by the creation of partnerships between the LGUs and the partner in particular. Within these activities in capacity building, there is a clear gap to identify and develop what kind of training is needed for the local political leaders to improve their commitment and understanding of DRR (Jeremy, 2014).

It was not only the landfall of typhoon Yolanda and the winds and rains associated with it, but the sea surge that came with it, creating a pseudo-tsunami in the coastal areas which went up to $1 \mathrm{~km}$ inland, that created a disastrous situation.

The international response produced a big influx of resources into the country as well as a "reality check" for the Filipino authorities. In many cases, Local Governments and Local NGOs were not aware of the cluster system for coordination of resources and not understand the how and where to request their needs (Alcayna et al., 2016).

It was as of June of 2014, just 5 months after the impact of Hayian, when there was a new, updated and comprehensive document published; the National Disaster Response Plan (NDRP), supported by JICA (Japanese Cooperation) (Matsuoka \& Shaw, 2014).

It is during 2014, with the influx of resources when the different departments in charge of a disaster response such as the Department of Health (DoH), the Department of Interior and Local Governance (DILG) and the Office of Civil Defence (OCD) started to improve and polish their protocols and procedures.

On the other hand, the national and internal governance bodies become a challenge for the coordination of activities from the INGOs due to the described difficulties of balancing the central structures with the peripheral and local authorities (Carabine, 2015). Then again, each and every one of the local government Health Emergency Preparedness Responses and Recovery Plans include specific hazard assessments for their areas (Wridt, Seley, Fisher, \& DuBois, 2014). Considering both issues, we find ourselves in a scenario where valuable documents are generated at different levels, but that would find benefits from each other if communication between governmental levels was improved.

Sensitization campaigns happened both for the population and for the Decision makers at all levels, from barangay up to National level providing the opportunity and the will.

The frameworks described have a 5 to 10 -year validity and are documents in progress, with theoretical deadlines, which in rare cases are respected and the objectives achieved.

General recommendations for the construction of the DRR of the Philippines in the future should include:

1) Creation of a single database, including definitions for communities, the 
different levels and links between them of the different organizational levels of the country that can be used throughout the whole archipelago.

2) More research is needed to implement the training, starting from basic knowledge going through needs assessment level and management, identifying the key stakeholders for each training and level. These trainings should be summative so as to create a single national training programme, where the different actors working in the country can participate and collaborate.

3) The development of the previous item should serve as a point of evolution to create a single area of the Filipino government in charge of the DRR and response, to which all the actors should report to, looking into the possibility of being able to map the 3 Ws.... who is doing what and where.

4) All of these activities will have the legal framework of the international documents and look forward to share knowledge, efforts and resources (if needed) between the neighbouring countries. Adding resources and experiences will ease the way.

\section{Conclusion}

The Philippines had the way to accomplish a good and sound DRR strategy and implement it countrywide since 2010. Being in one of the most vulnerable places in the planet for multi-hazards, it was a matter of time for a big disaster to happen, despite the fact that the "big one" is still expected to arrive, being this a mega earthquake such as the one in San Francisco in 1906.

The initial follow up of the Hyogo initiative with the creation of the NDRRMP was good and the way was started, but a reticence of will until 2013 and Haiyan avoided the evolution of the DRR activities the way that they should have.

Having an increasing number of in-depth documents such as the Hyogo Framework and the NDRRMP as references, complemented by the SNAP and the local identifiers of hazards, and being aware of their situation and vulnerability, should have been enough for the will of the Philippine community to implement it by providing the way. To be able to achieve this, vertical communication between LGUs and central government will be a key element.

It is time for the policy-makers and implementers to have the will by taking advantage of the way created.

\section{Author Contributions}

$\mathrm{AV}$ conducted the literature review, analyzed the data and was the principle author in writing the manuscript. NM, MR, DP, JG and JP provided guidance in methodological approaches, reviewed and commented on the manuscript. All authors read and approved the final manuscript.

\section{Conflicts of Interest}

The authors declare no conflicts of interest regarding the publication of this paper. 


\section{References}

Alcayna, T., Bollettino, V., Dy, P., \& Vinck, P. (2016). Resilience and Disaster Trends in the Philippines: Opportunities for National and Local Capacity Building. PLoS Currents, 8, ecurrents.dis.4a0bc960866e53bd6357ac135d740846.

APEC High Level Policy Dialogue on Disaster Resiliency-Thailand. https://reliefweb.int/report/thailand/apec-high-level-policy-dialogue-disaster-resiliency

Asia Meets to Implement Sendai Framework-World. https://reliefweb.int/report/world/asia-meets-implement-sendai-framework

Asian Conference on Disaster Reduction 2006 (ACDR 2006) (2007). Towards the Realization of the Strategic Goals of the Hyogo Framework for Action (HFA) 2005-2015: Summary Report. Kobe: Asian Disaster Reduction Center.

Banwell, N., Montoya, J., Opeña, M., IJsselmuiden, C., Law, R., Balboa, G. J., Murray, V. et al. (2016). Developing the Philippines as a Global Hub for Disaster Risk Reduction-A Health Research Initiative as Presented at the 10th Philippine National Health Research System Week Celebration. PLoS Currents, 8, pii: ecurrents.dis. 5 cf90566bb7791456dcf6b9baf6d4873. https://doi.org/10.1371/currents.dis.5cf90566bb7791456dcf6b9baf6d4873

Banwell, N., Rutherford, S., Mackey, B., \& Chu, C. (2018). Towards Improved Linkage of Disaster Risk Reduction and Climate Change Adaptation in Health: A Review. International Journal of Environmental Research and Public Health, 15, 793. https://doi.org/10.3390/ijerph15040793

Brassard, C., Giles, D. W., \& Howitt, A. M. (2015). Natural Disaster Management in the Asia-Pacific: Policy and Governance. Berlin: Springer.

https://doi.org/10.1007/978-4-431-55157-7 http://public.eblib.com/choice/publicfullrecord.aspx? $\mathrm{p}=1967288$

Burkle, F. M., Egawa, S., MacIntyre, A. G., Otomo, Y., Beadling, C. W., Walsh, J. T. et al. (2014). The 2015 Hyogo Framework for Action: Cautious Optimism. Disaster Medicine and Public Health Preparedness, 8, 191-192. https://doi.org/10.1017/dmp.2014.50

Carabine, E. (2015). Revitalising Evidence-Based Policy for the Sendai Framework for Disaster Risk Reduction 2015-2030: Lessons from Existing International Science Partnerships. PLoS Currents, 7, pii: ecurrents.dis.aaab45b2b4106307ae2168a485e03b8a. https://doi.org/10.1371/currents.dis.aaab45b2b4106307ae2168a485e03b8a

Egawa, S., MacIntyre, A. G., Beadling, C. W., Walsh, J. T., \& Shimomura, O. (2014). International Symposium on Disaster Medicine and Public Health Management: Review of the Hyogo Framework for Action. Disaster Medicine and Public Health Preparedness, 8, 357-358. https://doi.org/10.1017/dmp.2014.85

Guha-Sapir, D., Vos, F., Below, R., Ponserre, S., Centre for Research on the Epidemiology of Disasters, WHO Collaborating Centre for Research on the Epidemiology of Disasters et al. (2012). Annual Disaster Statistical Review 2011: The Numbers and Trends. Brussels: Centre for Research on the Epidemiology of Disasters.

Intergovernmental Panel on Climate Change (2015). Climate Change 2014: Impacts, Adaptation and Vulnerability.

James, J. J. (2014). Supporting Health in the Hyogo Framework for Action-2. Disaster Medicine and Public Health Preparedness, 8, 193. https://doi.org/10.1017/dmp.2014.51

Jeremy, H. (2014). Experiences of National Governments in Expanding Their Role in Humanitarian Preparedness and Response (p. 96).

Kabil, A., \& Kabeil, M. M. (2011). Initial Requirements of National Crisis Decision Sup- 
port System.

Manyena, S. B. (2006). The Concept of Resilience Revisited. Disasters, 30, 433-450. https://doi.org/10.1111/j.0361-3666.2006.00331.x

Matsuoka, Y., \& Shaw, R. (2014). Hyogo Framework for Action and Urban Disaster Resilience. http://public.eblib.com/choice/publicfullrecord.aspx? $\mathrm{p}=1812222$ https://doi.org/10.1108/S2040-726220140000016013

Philippines: Strategic National Action Plan (SNAP) for Disaster Risk Reduction 2009-2019. https://www.preventionweb.net/english/professional/policies/v.php?id=60250

Towards Policy Integration of Disaster Risk, Climate Adaptation, and Development in ASEAN: A Baseline Assessment-World.

https://www.rsis.edu.sg/wp-content/uploads/2017/01/NTS-insight-Towards-Policy-Int egration-of-DRR-CCA.pdf

Vereinte, N., \& Office for Disaster Risk Reduction (2015). Making Development Sustainable the Future of Disaster Risk Management.

Wridt, P., Seley, J. E., Fisher, S. E., \& DuBois, B. E. (2014). Participatory Mapping Approaches to Coordinate the Emergency Response of Spontaneous Volunteers after Hurricane Sandy. International Journal of E-Planning Research (IJEPR), 3, 1-19. https://doi.org/10.4018/ijepr.2014070101

\section{Abbreviations and Symbols}

DRR: Disaster Risk Reduction

DRRM: Disaster Risk Reduction Management

LGU: Local Government Unit

MDG: Millennium Development Goals

NDRRMP: National Disaster Response and Recovery Management Plan

RA: Republic Act

HFA: Hyogo Framework of Action 